\title{
Grommets and swimmers ear
}

\section{Mashudu Tshifularo*}

ENT department, Steve Biko Academic Hospital

University of Pretoria

*Corresponding author, email: mashudu.tshifularo@up.ac.za

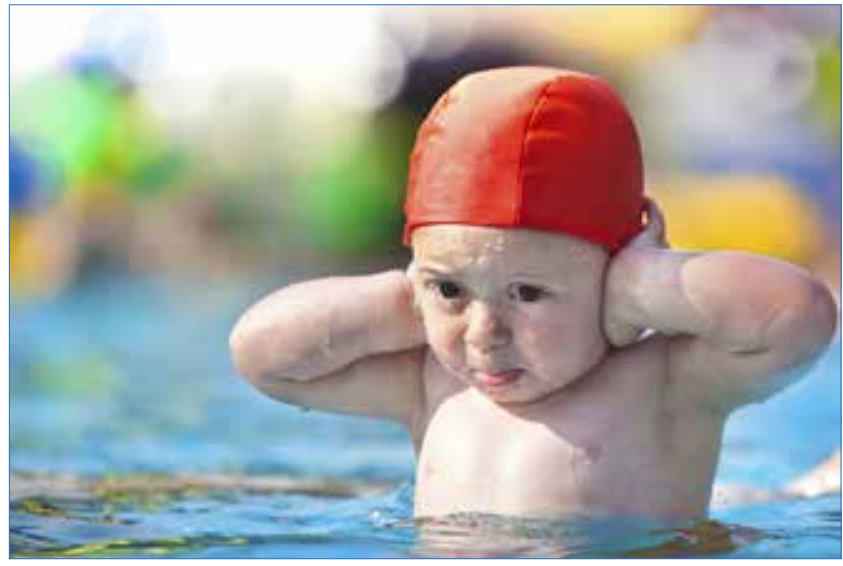

Background

Acute otitis media (AOM) is one of the most common childhood illnesses. While many children experience sporadic AOM episode, an important group suffer from recurrent AOM (rAOM), defined as three or more episodes in six months or four or more in one year. In this subset of children AOM poses a true burden through frequent episodes of ear pain, irritation, restlessness, pyrexia, general illness, sleepless nights and time lost from nursery or school. This group of children will suffer from poor language and school progress and will require temporary transient relief with ventilation tubes (grommets) or tympanotomy tubes can be offered for rAOM. Myringotomy with tympanostomy tubes is the most common otological surgery. 1,2,3

Most surgeons advise that the child's ears be kept dry during the immediate post-operative period when grommets are still in situ. Some surgeons will permit swimming or bathing or playing water sports (games). Others will recommend preventions earplugs, headbands and avoidance of water exposure to reduce ear infections. However a range of differing conclusions exist regarding the need for water prevention precautions, with wide variation in clinical practice.

\section{Objectives}

To present Cochrane and Literature review on the opinions of the role of water/swimmer precautions in children with ventilation tubes (grommets).

\section{Search methods}

The Cochrane ENT trials search register, central register of trials (central 2018), Pubmed, EMBASE, WEB of science, clinical trial. gov, and additional sources for published articles. The month of the search was September 2018.

\section{Selection criteria}

Randomised controlled trials recruiting children (0-17 years) with ventilation tubes and assessing the effect of water precautions (Avoidance or swimming/bathing restrictions) and mechanical (earplugs, moulds, swim seal, hats, bands) and review articles on the recent same topics.

\section{Grommets (Ventilation tube)}

These are tiny tubes made of different materials (plastic, metal, etc.) put in the eardrums as temporary on artificial eutascian tube. They are to improve middle ear ventilation, hearing improvement and drainage when eutascian tube is blocked in otitis media with effusion.

\section{Grommets}

Grommets are inserted under general anaesthesia as day procedures, while myringotomy and drainage aspiration of fluid are done. It can be done with adenoidectomy and/ or tonsillectomy, if indicated. Grommets are not a cure but a temporary drainage and ventilation of the middle ear to improve

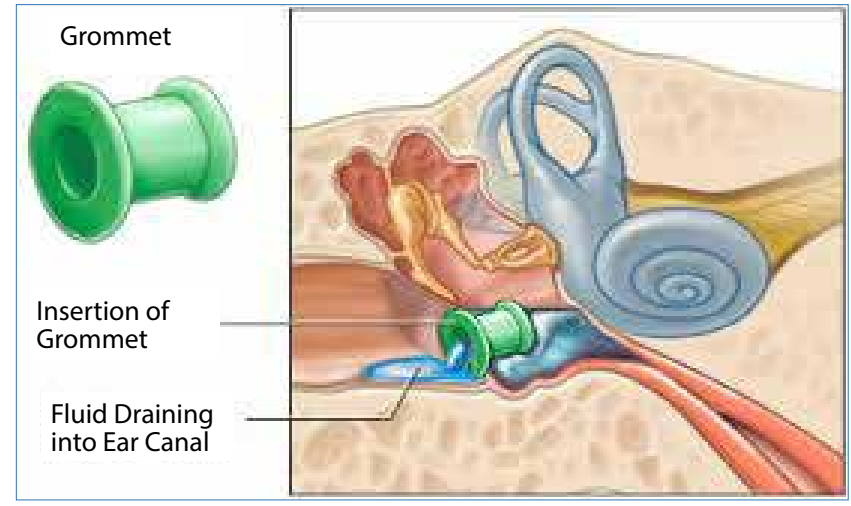

Figure 1: Grommet in-situ 


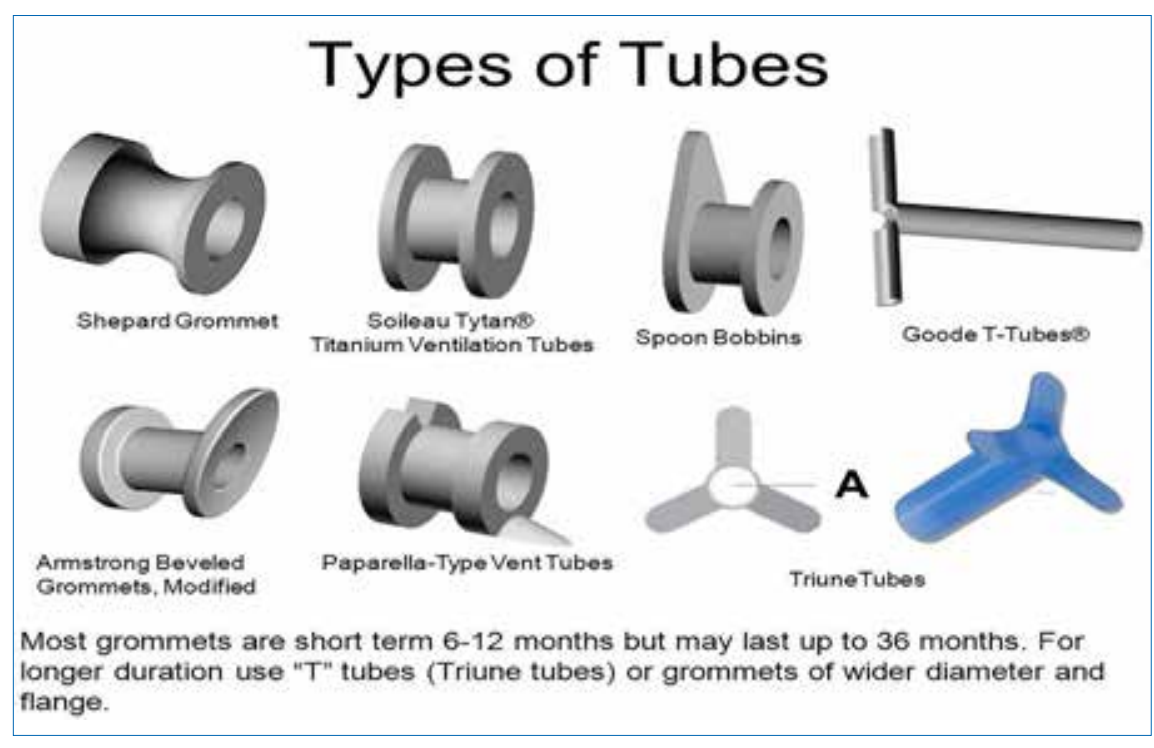

Figure 2: Types of grommets short and long term

the hearing until they grow out of it by 13-14 years of age - otitis media with effusion. In cleft palate affecting Eustachian tube they may be permanently inserted.

\section{Types of grommets}

There are three types, short (6-8 months), medium (8months2years) and long term (years until removed) grommets. Short term grommets can mostly fall out by themselves.

\section{Discharging ear post grommets insertion}

The function of grommets is to drain fluid from the middle ear and ventilate the middle ear. Post grommets discharges are normal and expected after grommets insertion not necessary due to middle ear infection.
The patients may have discharges with or without exposure to water (swimming). The absolute reduction in the episode of otorrhea appears to be very small unlikely to be clinically significant. The long term complications of grommets are Biofilm (discharges), perforation, cholesteatoma, tympanosclerosis and hearing loss. The rate of otorrhea ranges from $3.5 \%-41 \%$ in different studies (Table I) ${ }^{4}$. They all show significant number of otorrhea in children with grommets, irrespective of swimming. This is not surprising because the children for grommets are those with recurrent otitis media with effusion group already susceptible to chronic infection the function of grommets is to drain fluid (so otorrhea means the grommets are doing their job).

\section{Does water pass through grommets?}

Marks and Mills in (1983) theorized that before water passes through a grommet the tympanic membrane must be fixed and like in impedance studies $10-20 \mathrm{~cm} \mathrm{H}_{2} \mathrm{O}$ of pressure..$^{4,5}$ It will take $2.8 \mathrm{~cm} \mathrm{H}_{2} \mathrm{O}$ pressure to push water through a $1.1 \mathrm{~mm}$ grommet, hence needing between 12.8 to $22.8 \mathrm{~cm} \mathrm{H}_{2} \mathrm{O}$ pressure to push water through a grommet into the middle ear. Pashley and Scholl (1984) indicated that the pressure of soapy water was little lower at $1.68 \mathrm{~cm} \mathrm{H}_{2} \mathrm{O}$ and for Corticosporin otic drop it is $0.9 \mathrm{~cm}$ $\mathrm{H}_{2} \mathrm{O} .{ }^{6}$ Both authors concluded that in the case of normal surface swimming, bathing and hair washing, it is unlikely that water will enter the middle ear, but when the child dives (underwater) may be at risk. ${ }^{4}$

Table I: Summary of papers recording rates of otorrhoea in children with grommets ${ }^{4}$

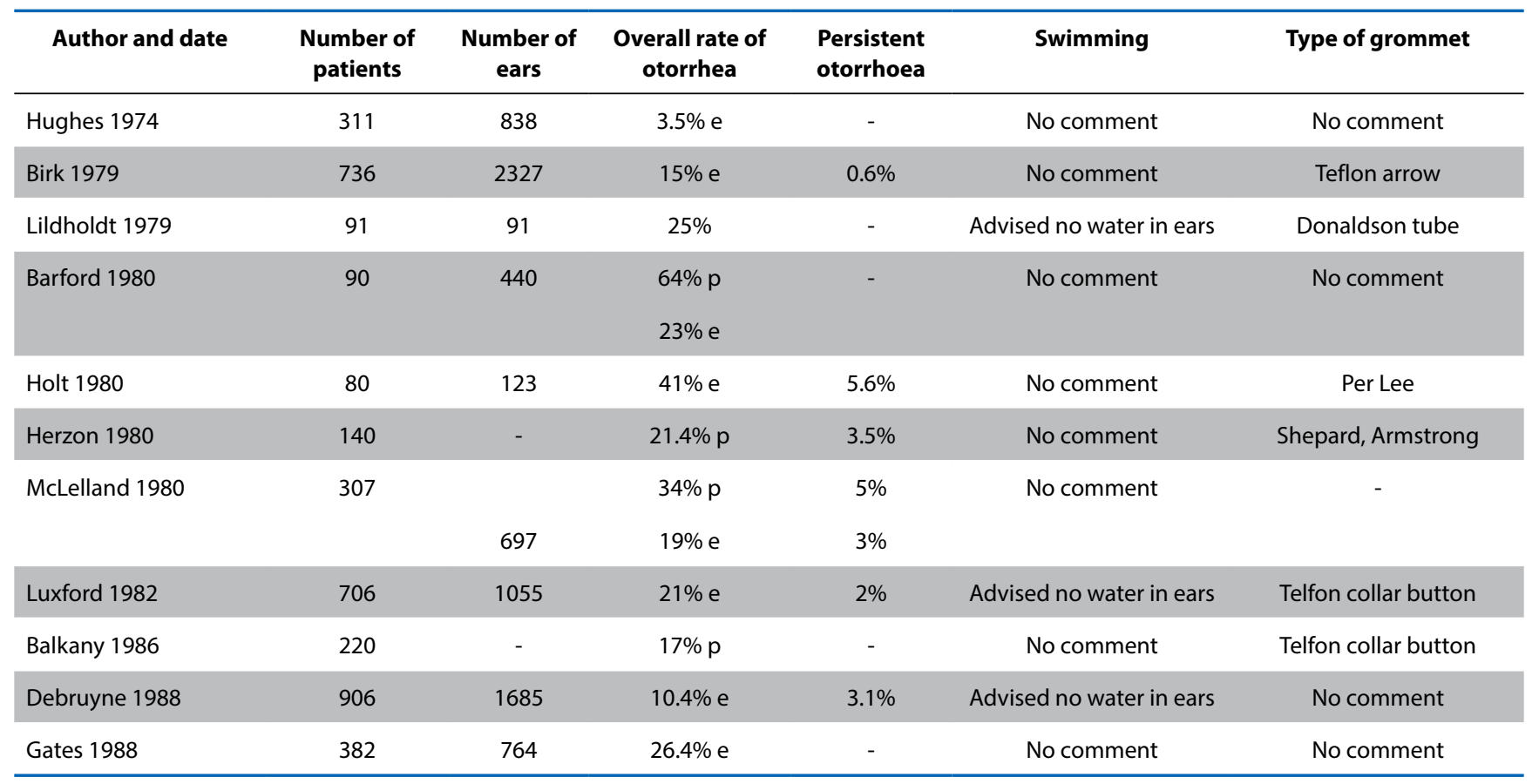

e = percentage of EARS with otorrhoea

$\mathrm{p}=$ percentage of PATIENTS with otorrhoea. 
They also concluded that a functioning Eustachian tube like in normal ears is necessary to allow water into the middle ear due to pressure changes by the Eustachian tube through the nasopharynx. It is possible that when grommets are used Eustachian tube function like in rAOM children is impaired so that higher pressures may be needed before water enters the middle ear., ${ }^{2,3}$ Roland (1978) proposed that it is safer for a child with a tendency to recurrent otitis media to swim with grommet in situ than without one. ${ }^{7}$ Grace et al (1987) concluded swimming may adversely affect middle ear pressure, which is not protected by grommets through the nasopharynx. ${ }^{8}$

\section{Does it matter if water enters middle ear?}

Smelt and Monkhouse (1985), found very little effects when sea water and swimming pool water are compared to normal saline controls but bath water showed more pronounced reaction and inflammation. ${ }^{9}$

\section{Grommets and swimming}

The earlier studies (Table II) show that whatever precautions are made very little benefit are derived because otorrhea is common after grommets. ${ }^{4}$

Earplugs appear to confer no benefit, and as Groves (1983) points out that, the occluded ears will muffle sounds and in order to be watertight, earplugs must fit well hence requiring close adult supervision. Both factors will decrease the fun and enjoyment of swimming. ${ }^{10}$

Cochrane database system review 2016 precaution for prevention of infection in children with ventilation tube (grommets). ${ }^{11}$

\section{Author's conclusion}

In conclusion, evidence suggests that swimming without ear protection can be safely permitted for children with grommets. ${ }^{11}$ It is probably advisable to warn parents firstly that otorrhoea is a recognised complication of grommets irrespective of swimming but that treatment is usually simple and effective; secondly there may be a slightly increased risk of infection if children dive; and thirdly, it would seem prudent to advise against dunking the head under the water at bath time. Chapman (1980) wrote that the advice to forbid swimming in children with grommets 'causes distress, delays the acquisition of a life-saving skill and is based on no published evidence ${ }^{4,2}$.

The baseline rate of ventilation tube otorrhoea and the morbidity associated with it is usually low and therefore careful prior consideration must be given to the efficacy, costs and burdens of any intervention aimed at reducing this rate. While there is some evidence to suggest that wearing ear plug reduces the rate of otorrhea in children with ventilation tubes, clinicians and parents should understand that the absolute reduction in the number of episodes of otorrhoea appears to be very small and is unlikely to be clinically significant. Based on the data

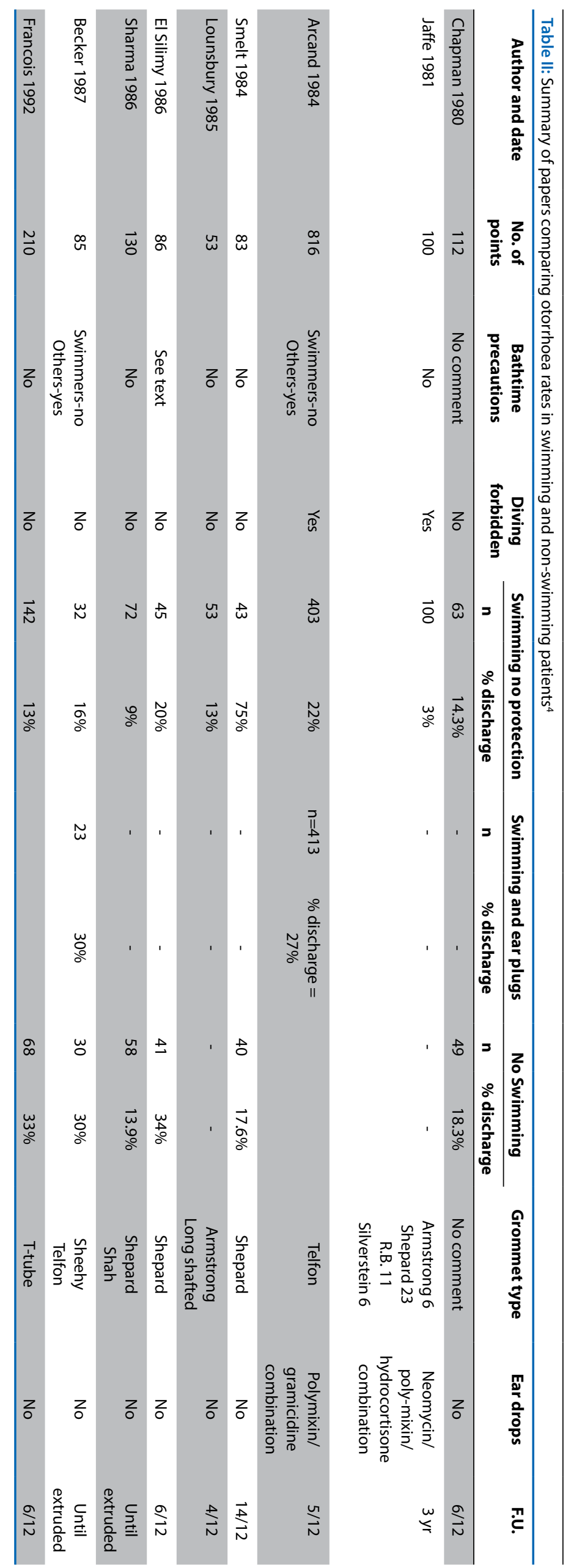


available, an average child would have to wear ear plugs for 2.8 years to prevent one episode of otorrhea. ${ }^{1,9,11}$ Some evidence suggests that advising children to avoid swimming or head immersion during bath does not affect rates of otorrhoea, although good quality data are lacking in this area. Currently, consensus guidelines therefore recommend against the routing use of water precautions on the basis that the limited clinical benefit is outweighed by the associated cost, inconvenience and anxiety. Future high-quality studies could be undertaken but may not be thought necessary. It is uncertain whether further trials in this area would change the findings of this review or have an impact on practice. Any future high-quality research should focus on determining whether particular groups of children benefit more from water precautions that others, as well as on developing clinical guidelines and their implementation. ${ }^{1,2,10,11}$

\section{References}

1. Chapman, D. F. (1980) Swimming and grommets. Clinical Otolaryngology 5:420

2. Lau L, Mick P, Nunez DA. Conchrane Database Syst Rev. Grommets (ventilation tubes) for recurrent acute otitis media in children. PubMed. April 2018
3. Mao-Che Wang, Chia-Yu Liu, An-Suey Shiao, Tyrone Wang. Ear problems in Swimmers. J Chin Med Assoc. August 2005. Vol 68. No 8

4. MB Pringle. Grommets, swimming and otorrhoea - a review. The journal of Laryngology and Otology. March 1993, Vol.107,pp.190-194

5. Marks N.J., Mills, R.P. (1983) Swimming and grommets. Journal of the Royal Society of Medicne 76: 23-26

6. Pashley, N.R., Scholl, P.D. (1984) Tympanostomy tubes and liquids - an in-vitro study. Journal of Otolaryngology 13: 296-298

7. Roland, P. E. (1978) Grommets and swimming. British Medical Journal 2: 1301

8. Grace, A., Ryan, R., Durham, L., Johnson, A. (1987) The effect of swimming in chlorinated water on middle ear pressure. Journal of Otolaryngology 164 228-230

9. Smelt, G.J., Monkhouse, W.S. (1985) The effect of bath water, sea water and swimming on the guinea pig middle ear. Journal of Laryngology and Otology 99: 1209-1216

10. Groves, J. (1983) Grommets and swimming. Editorial. Journal of the Royal Society Medicine 76: 6

11. Moualed D, Masterson L, Kumar S, Donnely N. Conchrane Database Syst Rev. Water precautions for prevention of infection in children with ventilation tubes (grommets). PubMed. January 2016

12. All the figures are from Google 